\title{
Article \\ High-Performance Humidity Sensor Based on the Graphene Flower/Zinc Oxide Composite
}

\author{
Muhammad Saqib ${ }^{1}$, Shenawar Ali Khan ${ }^{1}$, Hafiz Mohammad Mutee Ur Rehman ${ }^{1}$, Yunsook Yang ${ }^{1}$, \\ Seongwan Kim ${ }^{1}$, Muhammad Muqeet Rehman ${ }^{1}$ and Woo Young Kim 1,2,*(D) \\ 1 Faculty of Applied Energy System, Major of Electronic Engineering, Jeju National University, Jeju 63243, \\ Korea; saqibmuhammad@jejunu.ac.kr (M.S.); shenawaralikhan@jejunu.ac.kr (S.A.K.); \\ mutee1990@jejunu.ac.kr (H.M.M.U.R.); yunsuk0001@jejunu.ac.kr (Y.Y.); pea8543@jejunu.ac.kr (S.K.); \\ muqeet1988@jejunu.ac.kr or muqeetmughal88@gmail.com (M.M.R.) \\ 2 Department of Electronic Engineering, Jeju National University, Jeju 63243, Korea \\ * Correspondence: semigumi@jejunu.ac.kr
}

Citation: Saqib, M.; Ali Khan, S.; Mutee Ur Rehman, H.M.; Yang, Y.; Kim, S.; Rehman, M.M.; Young Kim, W. High-Performance Humidity Sensor Based on the Graphene Flower/Zinc Oxide Composite. Nanomaterials 2021, 11, 242. https://doi.org/10.3390/nano 11010242

Received: 28 November 2020

Accepted: 13 January 2021

Published: 18 January 2021

Publisher's Note: MDPI stays neutral with regard to jurisdictional claims in published maps and institutional affiliations.

\begin{abstract}
Performance of an electronic device relies heavily on the availability of a suitable functional material. One of the simple, easy, and cost-effective ways to obtain novel functional materials with improved properties for desired applications is to make composites of selected materials. In this work, a novel composite of transparent n-type zinc oxide $(\mathrm{ZnO})$ with a wide bandgap and a unique structure of graphene in the form of a graphene flower $(\mathrm{GrF})$ is synthesized and used as the functional layer of a humidity sensor. The $(\mathrm{GrF} / \mathrm{ZnO})$ composite was synthesized by a simple sol-gel method. Morphological, elemental, and structural characterizations of $\mathrm{GrF} / \mathrm{ZnO}$ composite were performed by a field emission scanning electron microscope (FESEM), energy-dispersive spectroscopy (EDS), and an x-ray diffractometer (XRD), respectively, to fully understand the properties of this newly synthesized functional material. The proposed humidity sensor was tested in the relative humidity (RH) range of $15 \% \mathrm{RH} \%$ to $86 \% \mathrm{RH} \%$. The demonstrated sensor illustrated a highly sensitive response to humidity with an average current change of $7.77 \mu \mathrm{A} / \mathrm{RH} \%$. Other prominent characteristics shown by this device include but were not limited to high stability, repeatable results, fast response, and quick recovery time. The proposed humidity sensor was highly sensitive to human breathing, thus making it a promising candidate for various applications related to health monitoring.
\end{abstract}

Keywords: functional material; graphene flower and $\mathrm{ZnO}$ composite; sol-gel method; ultra-sensitive humidity sensor; fast response/recovery time; health monitoring applications

\section{Introduction}

Measurement of humidity is an essential factor for various industries including semiconductor fabs, pharmaceutical, food and beverage, agriculture, textile, refineries, paper and chemical industries, etc. [1]. The significance of humidity sensors can be estimated by evaluating its market value which was USD 901.7 million in 2018 and is expected to reach USD 1.6 billion by 2025 [2,3]. Among the available humidity sensors, relative humidity sensors are most widely used with maximum market shares [2,3]. Relative humidity sensors can be classified into several types depending on their operation such as resistive, capacitive, impedance, field-effect transistor (FET), optic-fiber, surface acoustic wave (SAW), etc. [4-6]. Resistive, capacitive, and impedance-based humidity sensors have similar device structure and are commonly used due to their facile fabrication, simplicity of operation, cost-effectiveness, and low driven power [5-7]. The performance of any type of humidity sensor is strongly dependent on the functional material which can bring good change to its electrical properties with respect to variation in humidity.

Presently, researchers are primarily focused on improving the characteristics of the functional material in humidity sensors by experimenting with various advanced materials and composites of existing materials and, therefore, several types of materials, including 
ceramics, polymers, biowastes, metal oxides, 2D materials, and their composites have been employed in humidity sensors [8-14]. Primarily, metal oxides such as $\mathrm{ZnO}, \mathrm{SnO}_{2}$, $\mathrm{Fe}_{2} \mathrm{O}_{3}, \mathrm{CuO}$, and $\mathrm{TiO}_{2}$ have been engaged in humidity sensing applications due to their unique electrochemical and electronic properties [15-18]. Among them, $\mathrm{ZnO}$ and its composites are widely used for humidity sensors due to their easy fabrication, low cost, high surface area, and high mobility of charge carriers [15,19-24]. Diverse structures of ZnO, including nanowires, nanorods, nanoparticles, and thin films have been used to improve various characteristics of a humidity sensor including its response time, recovery time, and range [25-29]. However, humidity sensors based on pure $\mathrm{ZnO}$ lack good sensitivity, limiting their use for various practical applications. Therefore, in order to use $\mathrm{ZnO}$ as the active material of a humidity sensor, it must be mixed with some other suitable material to overcome its deficiencies. Materials like metals, semiconductors, polymers, ceramics, and 2D materials have been used by different researchers to improve the humidity sensing properties of ZnO-based sensors [17,19-24].

The composite of $\mathrm{ZnO}$ with different $2 \mathrm{D}$ materials like graphene, $\mathrm{MoS}_{2}$, and $\mathrm{WS}_{2}$ illustrated great response to the change in humidity owing to their high surface to volume ratio, large surface area, and improved chemical and electrical properties [30-32]. Among these 2D materials, graphene was given great attention due to its excellent properties of high conductivity, the large specific surface area of $2600 \mathrm{~m}^{2} \mathrm{~g}^{-1}$, being optically transparent and having high chemical stability. Therefore, graphene and its derivative composites were widely investigated for the application of sensing change in humidity like $\mathrm{SnO}_{2} /$ reduced graphene oxide (RGO) [33], methyl red/graphene flakes [34], black phosphorous (BP)/graphene [35], lignosulfonate/RGO [36], BP/graphene oxide (GO) [37], non-woven fabric/GO [38], orange die/graphene [39], graphene/polyvinyl alcohol (PVA)/ $\mathrm{SiO}_{2}$ [40], chitosan/graphene quantum dots [41], etc. Studies have shown that the structure of graphene has a huge impact on the properties of the humidity sensor; therefore, graphene has been used in different forms with $\mathrm{ZnO}$ to enhance the humidity sensing behavior of $\mathrm{ZnO}$. These different structures of graphene and its derivatives include graphene flakes/ $\mathrm{ZnO}$ [30], graphene foam/ $\mathrm{ZnO}$ [42], graphene quantum dot/ $\mathrm{ZnO}$ nanowires [43], $\mathrm{ZnO} /$ polyvinylpyrrolidone (PVP)-RGO [44], ZnO/GO [45], etc. Improvement is still required in developing a longrange, stable, more sensitive, fast response and quick recovery time $\mathrm{ZnO}$-based humidity sensor that is easy to fabricate.

Herein, we propose a simple approach to fabricate and characterize the humidity sensor based on the composite of $\mathrm{ZnO}$ with graphene in the form of graphene flowers, a type of graphene that is directly synthesized based on a high rate CVD method using a bottom-up system. The proposed sensor showed a swift response time of a few milliseconds and a small recovery time of only $3 \mathrm{~s}$, excellent stability, and sensitivity to long-range relative humidity $(\mathrm{RH}) \%$. $\mathrm{ZnO}$ thin film was grown by the sol-gel method, and the thin film of graphene flowers was spray coated on $\mathrm{ZnO}$. GrF/ $\mathrm{ZnO}$ composite was characterized by a field emission scanning electron microscope (FESEM), energy-dispersive spectroscopy (EDS), and an X-ray diffractometer (XRD). The prepared sensor's electrical response was measured by an LCR meter and a precision source measurement unit at different $\mathrm{RH} \%$ levels.

\section{Experiment}

\subsection{Materials}

For the preparation of graphene flower (GF)-ZnO composite, zinc-acetate-dihydrate (ZAD), monoethanolamine (MEA), ethanol isopropyl-alcohol (IPA), acetone, and deionized water were purchased from Sigma-Aldrich, Seoul, Korea. Graphene flower (GF) solution in methyl-ethyl-ketone (MEK) (99.9 wt\%) was purchased from InALA, Kobe, Japan. All materials were used without modification while glass substrate and silver paste for patterning electrodes were purchased from MTI Korea. 
Nine types of different salts $\mathrm{LiCl}, \mathrm{CH}_{3} \mathrm{COOK}, \mathrm{CaCl}_{2}, \mathrm{~K}_{2} \mathrm{CO}_{3}, \mathrm{NaBr}, \mathrm{CuCl}_{2}, \mathrm{NaCl}$, $\mathrm{KCL}$, and $\mathrm{K}_{2} \mathrm{SO}_{4}$ were purchased from DAEJUNG Materials Korea to make supersaturated solutions for achieving different $\mathrm{RH} \%$ levels.

\subsection{Device Fabrication}

The entire process of device fabrication is illustrated in Figure 1. The glass was used as a substrate after cleaning it with acetone, isopropanol, and DI water for $30 \mathrm{~min}$ each followed by bath sonication. Interdigitated electrodes (IDE's) were fabricated on this cleaned glass substrate by using the technique of screen printing. The sample was treated with UV-ozone before depositing a thin film of active layer in order to enhance its adhesion to the surface. For the preparation of $\mathrm{ZnO}$ thin film, an optimum study for the best molar solution of ZAD was performed by using three different molar solutions $1 \mathrm{M}, 0.5 \mathrm{M}$, and $0.1 \mathrm{M}$ of ZAD in ethanol, and it was found that the 0.5-M solution was the best choice based on the obtained results as 0.1-M solution required a higher number of spin coating cycles to obtain the desired thickness while achieving a thin-film with the 1-M solution was not possible due to its high density. After UV-ozone cleaning of IDE's, a 0.5-M solution of ZAD and MEA in ethanol was spin coated on the substrate in two steps (500 rpm for $30 \mathrm{~s}$ and $1500 \mathrm{rpm}$ for $15 \mathrm{~s}$ ) followed by sintering at $150{ }^{\circ} \mathrm{C}$ for $20 \mathrm{~min}$ and the same process was repeated seven times to obtain a uniform thin film followed by annealing for one hour [46,47]. A solution of GrF in MEK solvent was spray coated on the already spin-coated thin film of $\mathrm{ZnO}$ followed by heating the sample at $150{ }^{\circ} \mathrm{C}$ for $1 \mathrm{~h}$ on a hotplate.

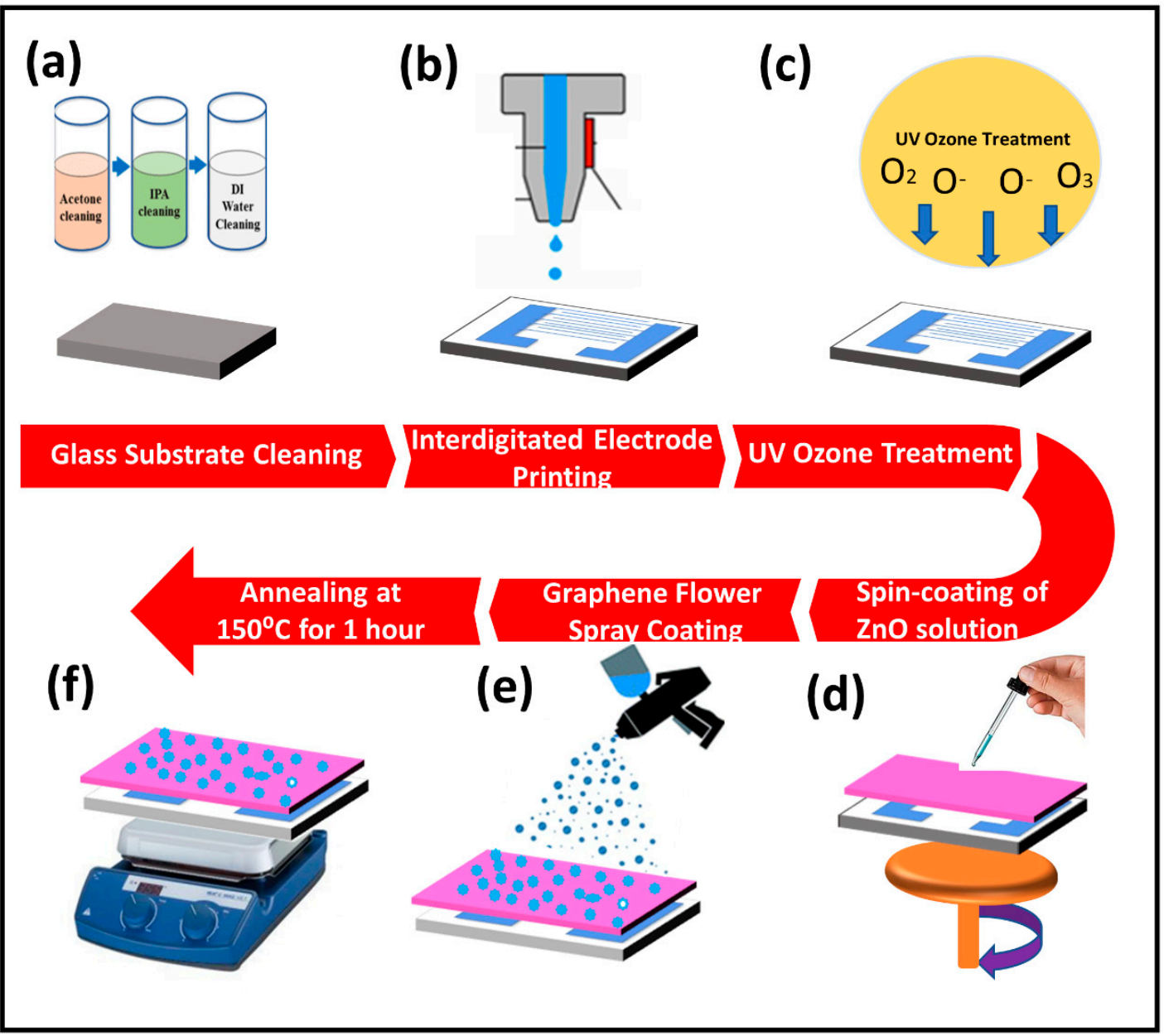

Figure 1. Process flow diagram: (a) substrate cleaning (b) electrode printing (c) UV-ozone treatment (d) sol-gel ZnO thin film deposition (e) graphene flower $(\mathrm{GrF})$ spray coating (f) annealing for $1 \mathrm{~h}$. 


\subsection{Device Characterization and Measurements}

Morphology of $\mathrm{ZnO}$ thin film and $\mathrm{GrF} / \mathrm{ZnO}$ composite was investigated by a field emission scanning electron microscope (FESEM) (TESCAN, Brno, Czech Republic, MIRA3) while the gap between the deposited electrodes was visualized with the help of an optical microscope (Olympus BX60, Tokyo, Japan). Figure S1 (supplementary data) shows the microscopic image of as-deposited electrodes with its finger width and distance between two fingers along with the complete picture of whole interdigitated electrodes. Energydispersive spectroscopy (EDS, Brno, Czech Republic) was used for the elemental analysis of the prepared composite films. Phase analysis of $\mathrm{ZnO}$ and $\mathrm{GrF} / \mathrm{ZnO}$ composite thin film was performed by an $\mathrm{X}$-ray diffractometer (Empyrean) using $\mathrm{Cu}$ target at the wavelength of $1.5406 \AA$, step size $0.02^{\circ}$ and scanning range from $5^{\circ}$ to $80^{\circ}$.

The experimental setup is shown in Figure 2; a supersaturated solution of different salts was used to achieve various $\mathrm{RH} \%$ levels in airtight glass jars to examine sensor response to humidity. The value of $\mathrm{RH} \%$ achieved in these jars is given in Table 1 . In the literature $[9,36]$, the reported $\mathrm{RH} \%$ level of different salt super-saturated solutions are lithium chloride $(11 \%)$, potassium acetate $(23 \%)$, calcium chloride $(33 \%)$, potassium carbonate $(43 \%)$, sodium bromide $(57 \%)$, sodium chloride $(67 \%)$, copper chloride $(87 \%)$ and potassium sulfate $(97 \%)$, but we achieved minimum $\mathrm{RH} \%$ of $15 \%$ with $\mathrm{LiCl}, \mathrm{CH}_{3} \mathrm{COOK}(23 \%)$, $\mathrm{CaCl}_{2}(32 \%), \mathrm{K}_{2} \mathrm{CO}_{3}(46 \%), \mathrm{NaBr}(60 \%), \mathrm{CuCl}_{2}(67 \%), \mathrm{NaCl}(72 \%), \mathrm{KCl}(80 \%)$ and maximum $\mathrm{RH} \%$ of $86 \%$ from $\mathrm{K}_{2} \mathrm{SO}_{4}$ super-saturated solution with an accuracy of $\pm 2 \%$. A commercially available humidity sensor, HTU21D, was used along with an Arduino board to calibrate the humidity level of supersaturated solutions. The device under test (DUT), i.e., the fabricated sensor, was placed in the desired $\mathrm{RH} \%$ environment by placing it inside the jar of corresponding salt solution for electrical measurements with respect to humidity. The used experimental setup is shown in Figure S2.

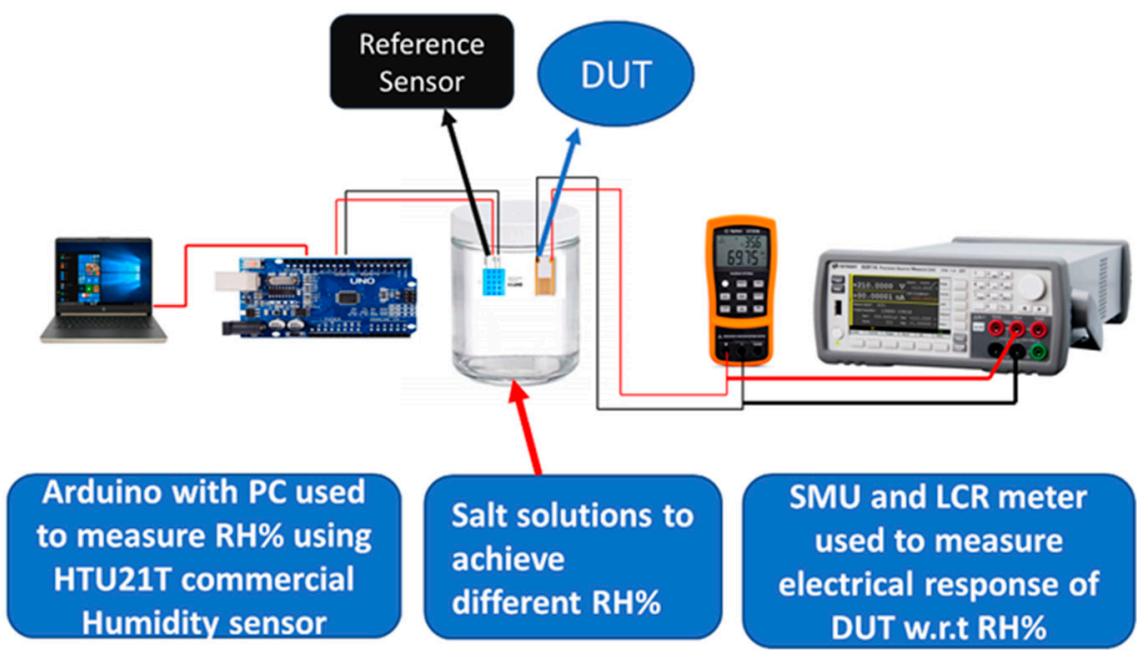

Figure 2. Experimental setup used for electrical measurement of the device under test (DUT).

Table 1. Relative humidity (RH)\% achieved in the airtight jar by the supersaturated solution of different salts.

\begin{tabular}{cccccccccc}
\hline Salt Solution & $\mathbf{L i C l}$ & $\mathbf{C H}_{3} \mathrm{COOK}$ & $\mathbf{C a C l}_{2}$ & $\mathbf{K}_{2} \mathbf{C O}_{3}$ & $\mathbf{N a B r}$ & $\mathbf{C u C l}_{2}$ & $\mathbf{N a C l}$ & $\mathbf{K C l}$ & $\mathbf{K}_{2} \mathbf{S O}_{4}$ \\
\hline $\mathbf{R H} \%$ & $15 \%$ & $23 \%$ & $32 \%$ & $46 \%$ & $60 \%$ & $67 \%$ & $72 \%$ & $80 \%$ & $86 \%$ \\
\hline
\end{tabular}

Change in the electrical properties of proposed humidity sensor with respect to change in $\mathrm{RH} \%$ were measured with different electronic devices such as LCR meter (KEYSIGHT U1733C) which was used to measure impedance and capacitive response of sensors with respect to different $\mathrm{RH} \%$ levels. A precision source measurement unit (KEYSIGHT 2911A) 
was used to measure current change with respect to $\mathrm{RH} \%$, response time, recovery time, stability, and different application tests of the proposed humidity sensor.

\section{Results and Discussion}

\subsection{Characterization of $\mathrm{ZnO}$ and $\mathrm{GrF} / \mathrm{ZnO}$ Composite}

An FESEM was used to examine the morphology of $\mathrm{GrF}, \mathrm{ZnO}$ and $\mathrm{GrF} / \mathrm{ZnO}$ thin films. For the uniform thin film of $\mathrm{ZnO}$ deposited by the sol-gel method, multiple spin coatings were required $[47,48]$. Therefore, a detailed study was done to find the effect of different spin coatings on $\mathrm{ZnO}$ thin films and samples with 1, 3, 5, 7, 9 and 11 cycles of spin-coating were examined by using FESEM and EDS analysis whose results are shown in Figure S3. The obtained results demonstrated that the thin film achieved after seven cycles of spin coating gave the best results and provided a uniform thin film, whereas the thin film of $\mathrm{ZnO}$ obtained for spin coating cycles of less than seven was non-uniform with different thicknesses at the center and edges.

Figure $3 a-c$, illustrates the FESEM images of GrF where the bright regions represent the edges of GrF; thus, a flower-like formation can be seen. FESEM images clearly show the high surface area and 3D structure of GrF. Figure 3d depicts the Raman spectroscopy analysis of graphene flowers at three different points. At all three points P1, P2 and P3 the Raman shift is approximately identical. From the ratio of $\mathrm{G}$ and $2 \mathrm{D}$ peaks, we can deduce that GrF has multiple layers.

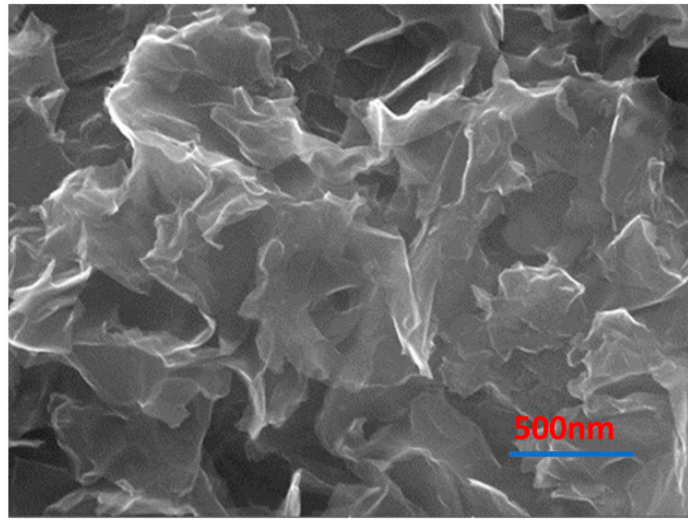

(a)

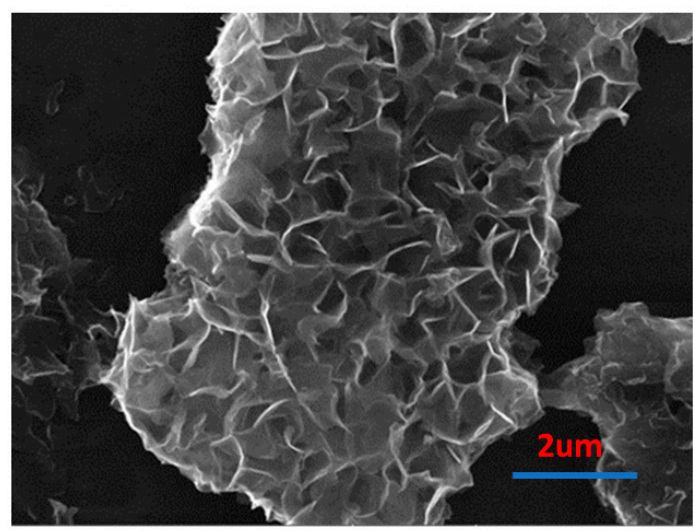

(c)

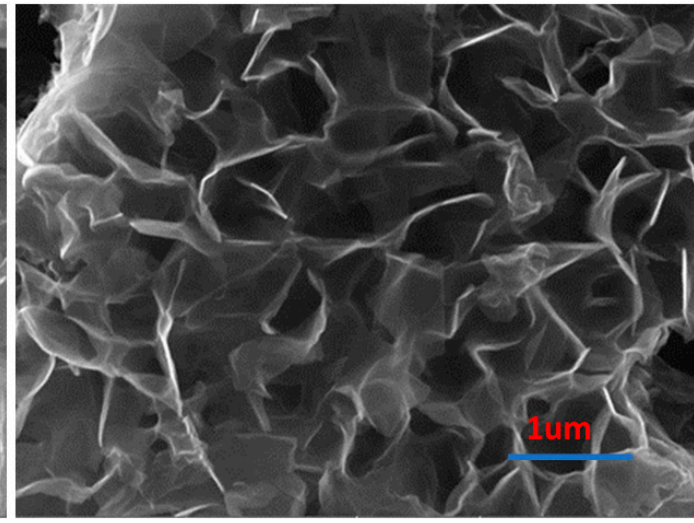

(b)

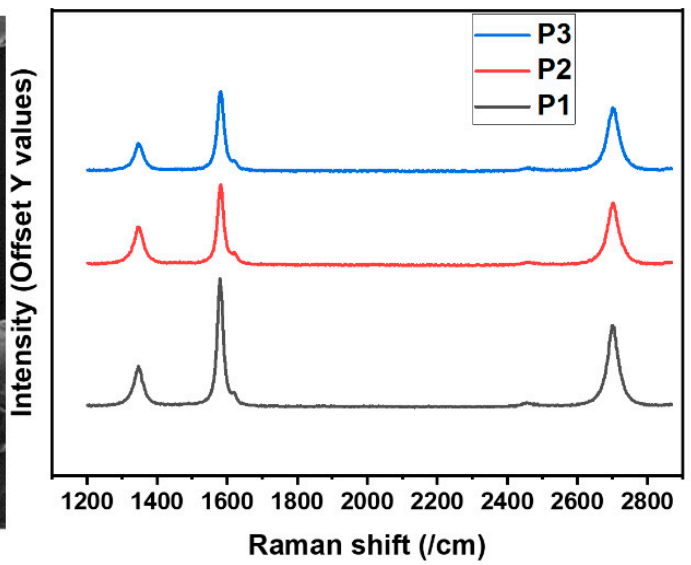

(d)

Figure 3. Characterization of graphene flowers, (a-c) field emission scanning electron microscope (FESEM) analysis, (d) Raman analysis. 
Figure 4a-c illustrate the surface morphology of the optimized $\mathrm{ZnO}$ thin film, revealing that $\mathrm{ZnO}$ has a relatively smooth surface. Figure $4 \mathrm{~d}-\mathrm{f}$ shows the morphology of the $\mathrm{GrF} / \mathrm{ZnO}$ composite, which clearly shows that it has pores and a greater surface area compared to pristine $\mathrm{ZnO}$ thin film. FESEM results confirmed that the $\mathrm{GrF} / \mathrm{ZnO}$ composite has a high surface area to volume ratio and pores that are essential for the functional material of any humidity sensor.
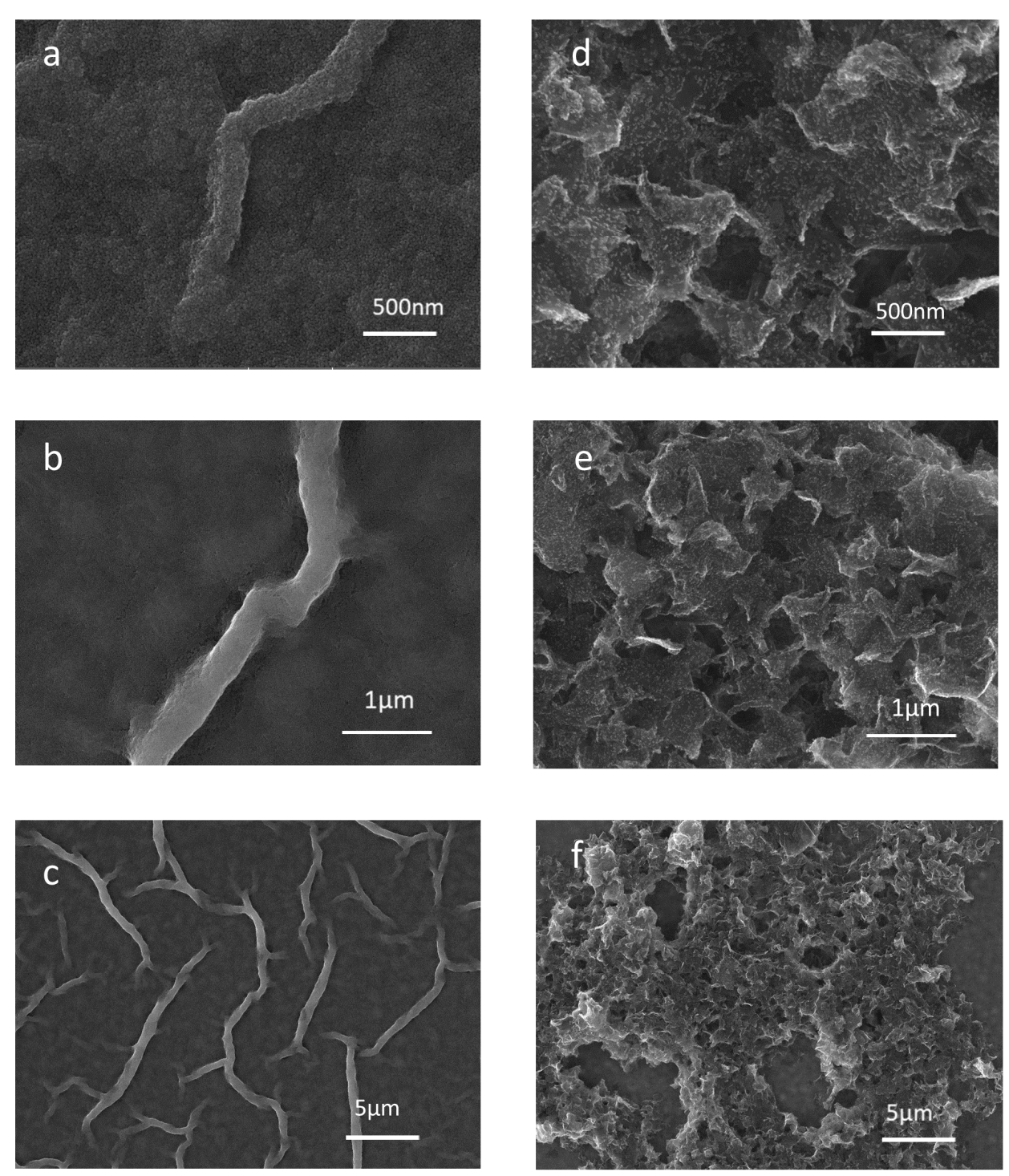

Figure 4. FESEM analysis of grown thin films, (a-c) SEM images of $\mathrm{ZnO}$ thin film at different magnifications; (d-f) $\mathrm{GrF} / \mathrm{ZnO}$ composite SEM images at various magnifications.

EDS analysis is usually used to confirm the elemental composition of the given samples; therefore, EDS analysis was performed to verify the successful synthesis of $\mathrm{ZnO}$ and $\mathrm{GrF} / \mathrm{ZnO}$ thin films. Samples were made on fluorine tin oxide (FTO)-coated glass to perform EDS analysis. EDS of FTO glass, $\mathrm{ZnO}$ thin film, and $\mathrm{GrF} / \mathrm{ZnO}$ is shown in Figure 5a-c. It is clearly shown in the EDS spectrum of FTO glass that tin (Sn) and oxygen were the only dominant elements with $w t \%$ of $73.66 \%$ and $23.43 \%$, respectively. Figure $5 b$ illustrates the EDS spectrum of $\mathrm{ZnO}$ thin film deposited on FTO glass by the sol-gel method; it confirms that $\mathrm{ZnO}$ thin film is grown successfully as zinc $(\mathrm{Zn})$ was present in the spectrum with wt $\%$ of approximately $60 \%$. Synthesis of $\mathrm{GrF} / \mathrm{ZnO}$ was also confirmed by EDS analysis shown in Figure 5c, illustrating the presence of carbon (C), zinc ( $\mathrm{Zn})$ oxygen $(\mathrm{O})$, and tin (Sn) at the $\mathrm{wt} \%$ of $21 \%, 15 \%, 36 \%$, and $25 \%$, respectively. 

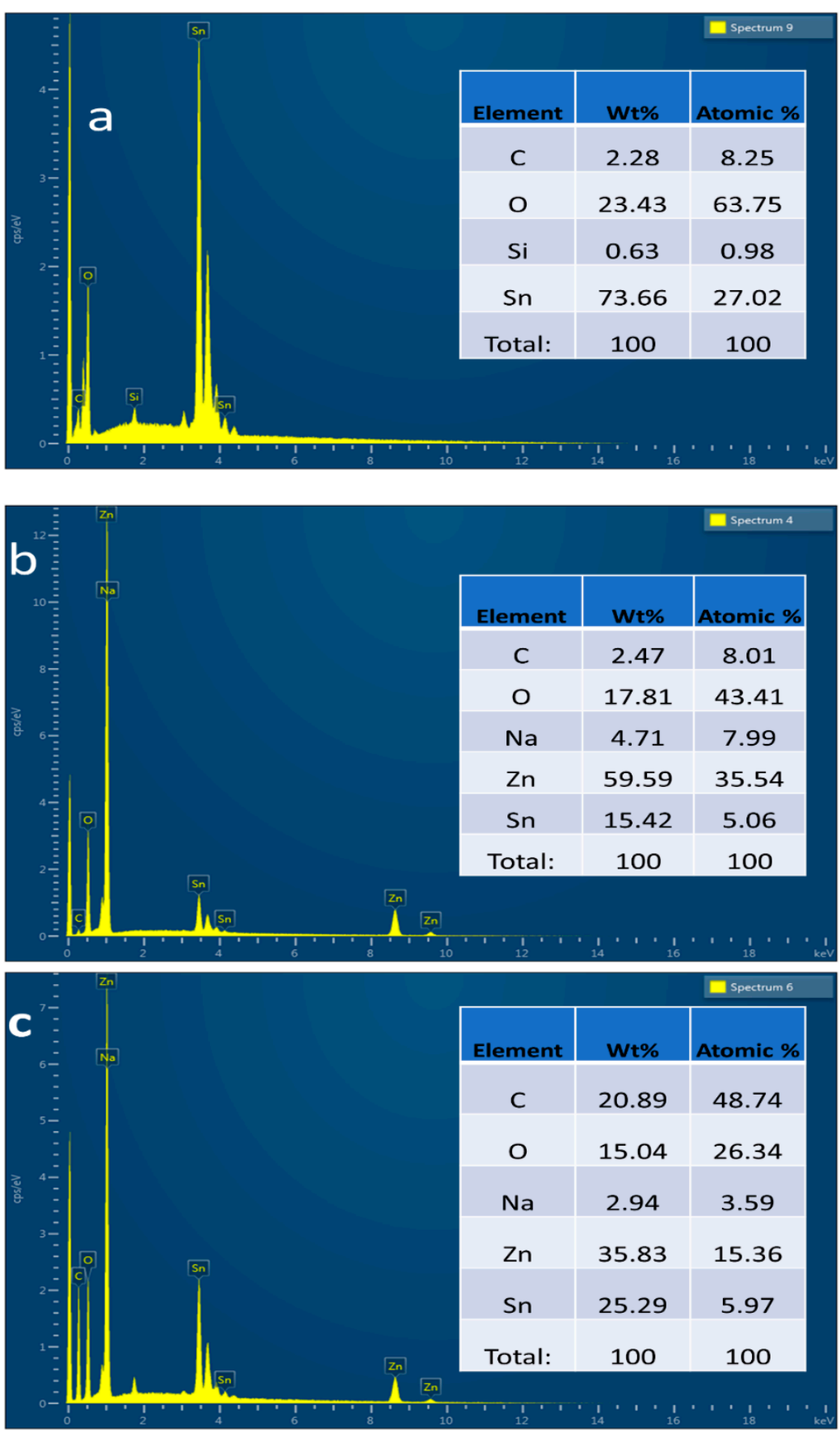

Figure 5. EDS analysis of, (a) EDS spectrum of fluorine tin oxide (FTO) glass (that was used as a substrate); (b) EDS spectrum of $\mathrm{ZnO}$ thin film; (c) $\mathrm{GrF} / \mathrm{ZnO}$ composite.

$\mathrm{XRD}$ analysis was performed to investigate the crystal structure of prepared $\mathrm{ZnO}$ and $\mathrm{GrF} / \mathrm{ZnO}$ thin films using the $\mathrm{X}$-ray diffractometer (Empyrean) at a step size of $0.02^{\circ}$ from $5^{\circ}$ to $80^{\circ}$. XRD analysis of $\mathrm{ZnO}$ thin film exhibited the peaks at $31.7^{\circ}, 34.4^{\circ}$, and $36.4^{\circ}$ as shown in Figure 6a, corresponding to lattice planes (100), (002) and (101), respectively, that confirm the hexagonal wurtzite structure of $\mathrm{ZnO}$ thin film according to joint committee of powder diffraction standards (JCPDS) card no. 36-1451 and also according to the literature [48]. In Figure 6b, XRD analysis of $\mathrm{GrF} / \mathrm{ZnO}$ composite is presented that shows the extra peak at $2 \theta=26^{\circ}$, which corresponds to (002) lattice plane of graphene [49,50] and peaks at $31.7^{\circ}, 34.4^{\circ}$, and $36.4^{\circ}$ correspond to lattice planes (100), (002) and (101) of $\mathrm{ZnO}$, respectively. 


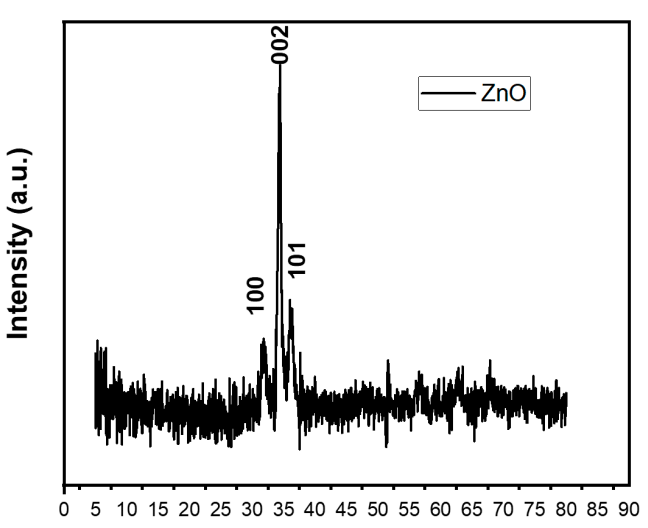

$2 \theta(\mathrm{deg})$

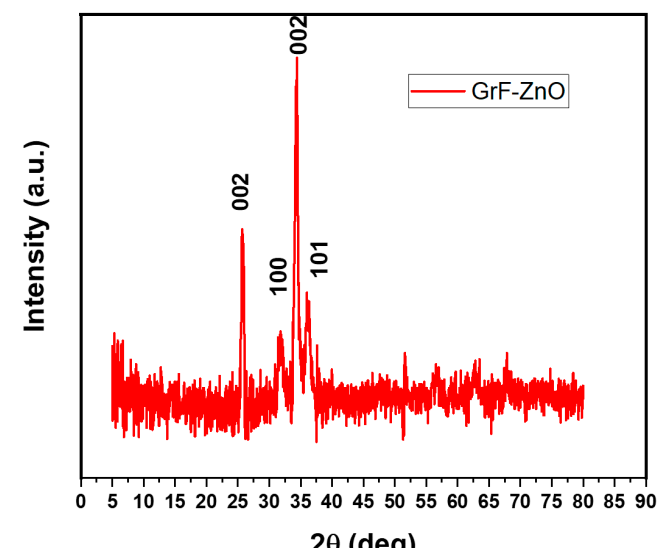

$2 \theta(\mathrm{deg})$

Figure 6. XRD analysis of (a) $\mathrm{ZnO}$ thin film; (b) GrF/ $\mathrm{ZnO}$ composite.

\subsection{Electrical Response of GrF/ZnO Composite with Respect to RH\%}

The experimental setup shown in Figure 2 was used to measure the proposed sensor's electrical response with respect to $\mathrm{RH} \%$. Different salt solutions were used to achieve various $\mathrm{RH} \%$ levels, ranging from $15 \%$ to $86 \% \mathrm{RH} \%$ by using supersaturated solutions of $\mathrm{LiCl}$ and $\mathrm{K}_{2} \mathrm{SO}_{4}$, respectively. A biased voltage of $3 \mathrm{~V}$ was given to the fabricated sensors using the KEYSIGHT B2911A Precision Source/Measure Unit, and the current was measured by placing the sensor at different $\mathrm{RH} \%$ levels. Figure 7a shows the change in current magnitude with respect to $\mathrm{RH} \%$. GrF/ZnO composite-based humidity sensor exhibited considerable change in the value of current at different $\mathrm{RH} \%$ levels ranging from a few nanoamperes to hundreds of microamperes. In the proposed sensor, we utilize graphene flowers (a 3D structure with large surface area) to make composite with $\mathrm{ZnO}$ for sensing humidity response. These graphene flowers are not electrically connected with each other. Initially, the active layer comprising $\mathrm{ZnO}$ and graphene flowers had a high resistance; however, resistance of this active layer can be decreased by forming an electrical connection between GrF such as through the absorption of water vapors. When humidity increases, water vapors fall on the sensing film, which makes an electrical connection between GrFs, resulting in an overall decrease in the value of resistance hence, allowing more current to flow between the two sets of IDEs. The 3D structure of GrF plays a vital role in providing a large surface area for the absorption of water vapors that results in a considerable increase in the conductivity of the $\mathrm{ZnO} / \mathrm{GrF}$ active layer. The trend of change in conductivity shown by our proposed device with absorption of water vapors is in line with other graphene-based humidity sensors reported in the literature $[4,29,36,41]$. Smith et al. [4] reported a decrease in resistance of graphene sheet with an increase in humidity level. S. Ali et al. [33] showed that resistance of graphene flakes/methyl red composite was decreased as $\mathrm{RH} \%$ increases. Moreover, as shown in Figure 7a, a pristine $\mathrm{ZnO}$-based device showed random current change over the $\mathrm{RH} \%$ change; initially, the change is approximately zero, whereas, after $60 \% \mathrm{RH}$, it shows a sharp change. It can be seen in Figure $7 \mathrm{~b}$ that the $\mathrm{GrF} / \mathrm{ZnO}$-based humidity sensor has shown a better current change over the whole $\mathrm{RH} \%$ range as compared to the pristine $\mathrm{ZnO}$-based humidity sensor. The characteristic of repeatability is also shown in Figure $7 b$, which exhibits the average measured current versus relative humidity for both $\mathrm{ZnO}$ and $\mathrm{GrF} / \mathrm{ZnO}-$ based humidity sensors. The error bars indicate the standard deviation of the data from their average value, with a maximum standard deviation of $10 \mu \mathrm{A}$ and $13 \mu \mathrm{A}$ for $\mathrm{ZnO}$ and GrF-ZnO-based humidity sensors, respectively. These data represent the repetition of the experiment nine times. Figure 7c illustrates the current response for the $\mathrm{GrF} / \mathrm{ZnO}$-based sensor upon exposure to different $\mathrm{RH} \%$ levels. The reversibility and reproducibility of the sensor was examined through exposure/recovery cycles for the sensor exposed from low $\mathrm{RH} \%$ to high $\mathrm{RH} \%$, and then conversely from high $\mathrm{RH} \%$ to low $\mathrm{RH} \%$. Figure $7 \mathrm{~d}$ shows the sensitivity 
graph of the GrF/ZnO-based humidity sensor. Sensitivity of the proposed sensor was found using the Equation (1).

$$
S=\frac{I_{R H}-I_{R H o}}{I_{R H o}} * 100 \%
$$

where $I_{R H o}$ is the value of current at $15 \% \mathrm{RH}$ and $\mathrm{I}_{\mathrm{RH}}$ is the value of current at exposure $\mathrm{RH} \%$.

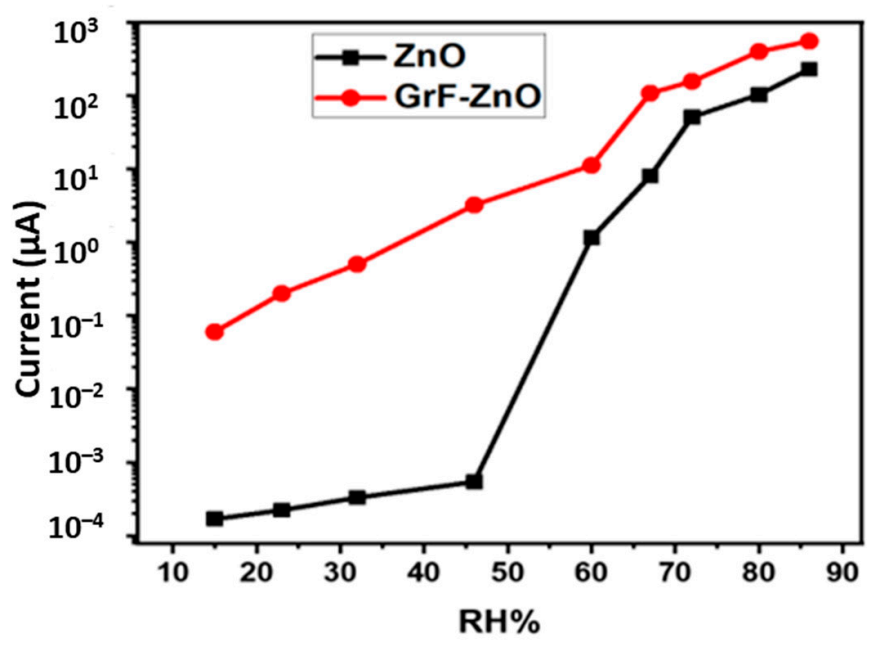

(a)

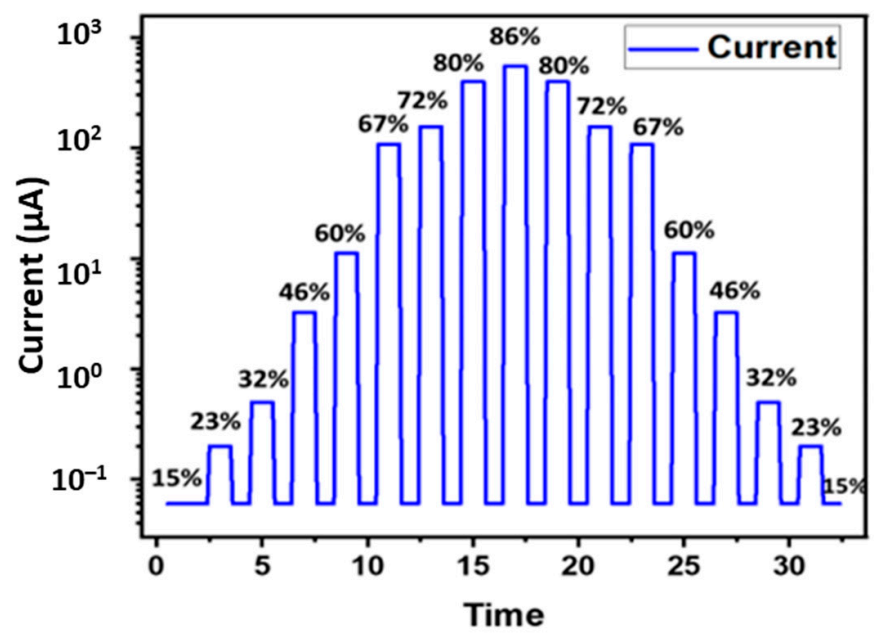

(c)

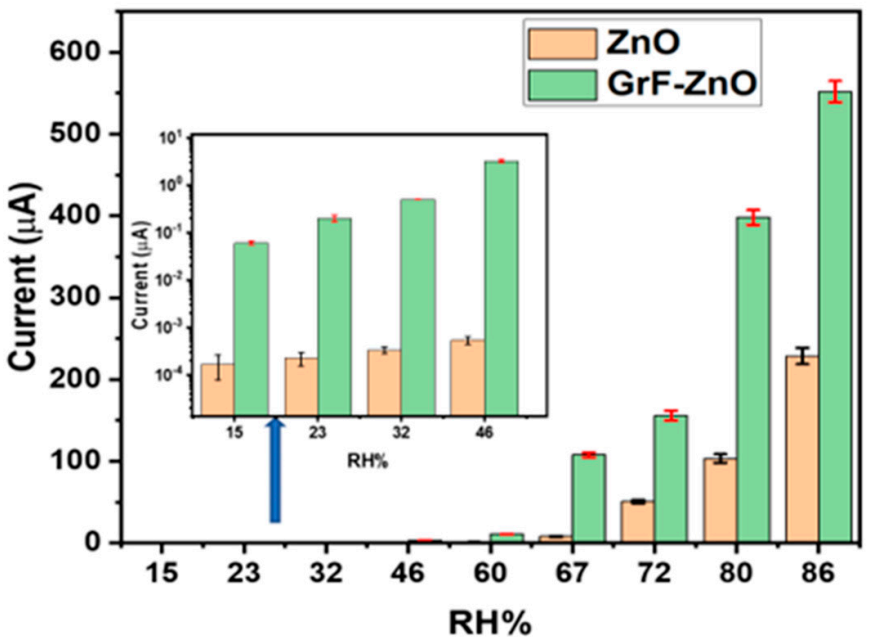

(b)

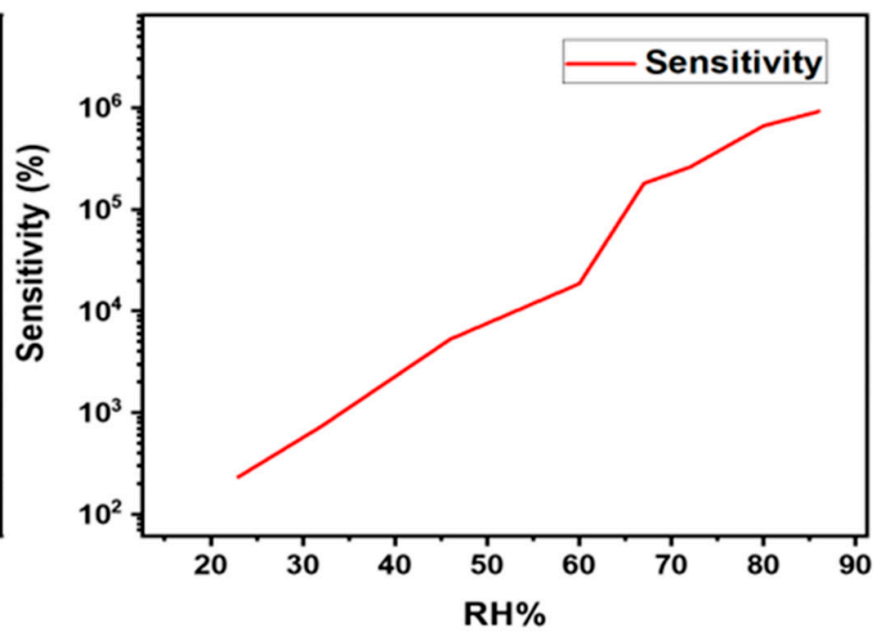

(d)

Figure 7. Electrical response with respect to $\mathrm{RH} \%$, (a) current vs. $\mathrm{RH} \%$; (b) repeatability analysis and comparison of current at different $\mathrm{RH} \%$ (inset shows the current comparison for low humidity levels); (c) current response of the $\mathrm{GrF}-\mathrm{ZnO}$ composite-based sensor under switching $\mathrm{RH}$; (d) sensitivity of $\mathrm{GrF}-\mathrm{ZnO}$ sensor.

Similarly, as current change over $\mathrm{RH} \%$ was measured, impedance and capacitance change with respect to $\mathrm{RH} \%$ was also measured using the KEYSIGHT U1733C LCR meter $\left(\mathrm{V}_{\mathrm{o}}=0.7 \mathrm{~V}\right.$ at different test frequencies of $1 \mathrm{kHz}, 10 \mathrm{kHz}$ and $\left.100 \mathrm{kHz}\right)$. Figure S4 shows the capacitance response with respect to $\mathrm{RH} \%$ for the $\mathrm{GrF} / \mathrm{ZnO}$-based humidity sensor. It shows that with the increase in the level of $\mathrm{RH} \%$, the value of capacitance also increases whereas impedance decreases as $\mathrm{RH} \%$ increases as shown in Figure S5. The inverse relation between $\mathrm{RH} \%$, and impedance can also be verified from the previous current vs. $\mathrm{RH} \%$ result and the literature $[4,36,41]$. 
Figure 8 depicts the current over voltage response of both electronic devices i.e., pristine $\mathrm{ZnO}$ and $\mathrm{GrF} / \mathrm{ZnO}-$ based humidity sensors placed at a particular $\mathrm{RH} \%$ level. Devices were placed in a desired $\mathrm{RH} \%$ level jar initially for $20 \mathrm{~min}$ to stabilize the closed jar's humidity followed by applying the voltage sweep from $0 \mathrm{~V}$ to $3 \mathrm{~V}$ using the KEYSIGHT B2911A Precision Source/Measure Unit (interfaced with a PC), and the current was measured correspondingly. These electrical results shown in Figure 8a-d confirmed the ohmic behavior of the proposed device and also verified the previously obtained results that showed a direct relation between increase in current and increasing levels of humidity. Figure 8a-d clearly shows that the $\mathrm{GrF} / \mathrm{ZnO}$-based humidity sensor established a significant current change with respect to the applied voltage sweep at each $\mathrm{RH} \%$ level that confirms its ohmic behavior and the possibility of operation at low voltages. Figure $8 a, b$ shows that pristine the $\mathrm{ZnO}$-based humidity sensor has approximately zero current change with respect to applied voltage sweep at low humidity levels and low current change at high $\mathrm{RH} \%$ levels compared to the $\mathrm{GrF} / \mathrm{ZnO}$-based sensor whose results are provided in Figure $8 \mathrm{c}$,d. The obtained electrical results present a strong case for the $\mathrm{GrF} / \mathrm{ZnO}$-based humidity sensor with respect to operational power as well as it requires less power as compared to the pristine $\mathrm{ZnO}$-based sensor.

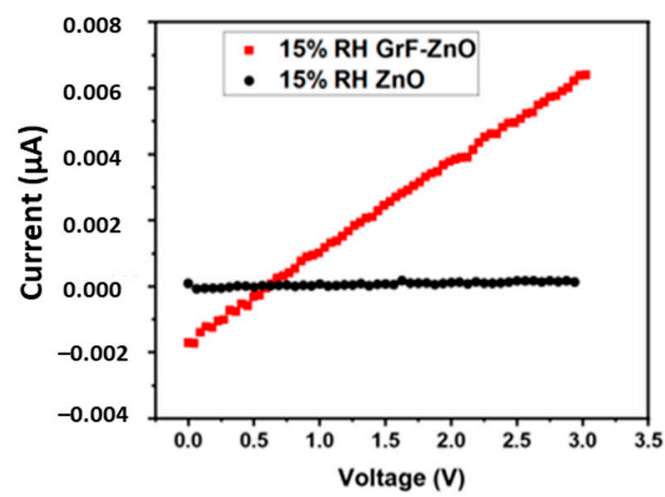

(a)

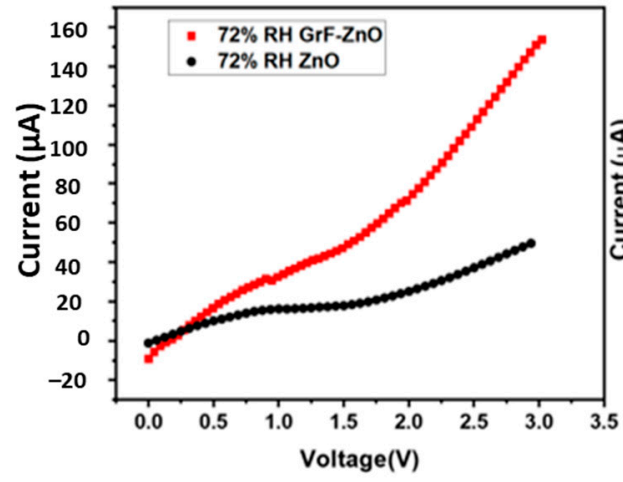

(c)

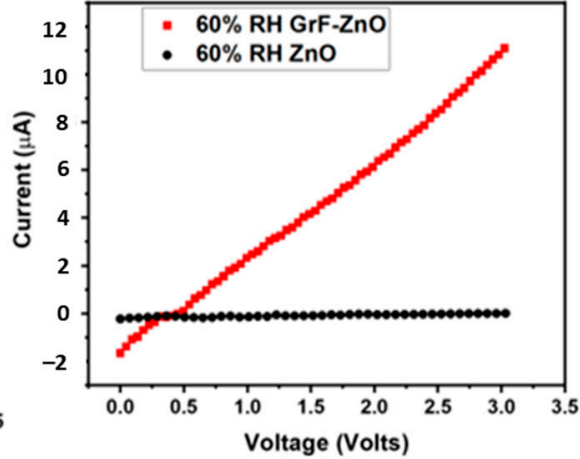

(b)

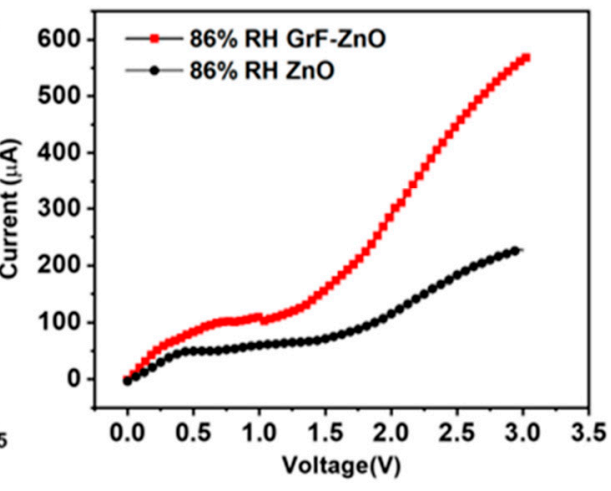

(d)

Figure 8. Current vs. voltage at different $\mathrm{RH} \%$, (a) $15 \% \mathrm{RH}$; (b) $60 \% \mathrm{RH}$, (c) $72 \% \mathrm{RH}$ and (d) $86 \% \mathrm{RH}$.

Response and recovery time are the essential features for any humidity sensor, and these are the main characteristics based on which sensors' performance can be evaluated. The response time is defined as the time required for the humidity sensor to reach $90 \%$ of the current change $(\Delta \mathrm{I})$ when the sensor is exposed to a given level of humidity. The recovery time is defined as the time needed to recover to $90 \%$ of the initial baseline after turning-off 
the humidity. Response and recovery time of the proposed sensor were measured by changing its position from one jar (low-level $\mathrm{RH} \%$ ) to the other jar (high-level $\mathrm{RH} \%$ ) which takes few minutes; therefore, response and recovery time measurement using this setup was not possible, so an alternate method was used. For measuring the response time, proposed sensor was moved from open air 35\% RH to $85 \%$ RH jar and recovery time was measured by moving back the proposed sensor from $85 \% \mathrm{RH}$ jar to open air. Figure 9a shows the response and recovery time graphs of our proposed sensor, illustrating a fast response $(0.4 \mathrm{~s})$ to humid air along with a short recovery time of just $4 \mathrm{~s}$. We compared our results with the earlier reported humidity sensors based on graphene sheet and found that these results are better than its counterparts $[4,29,42]$. Here we would like to mention that earlier we tested our humidity sensor in the range of $15 \%$ to $86 \%$ as shown in Figure $7 \mathrm{a}$; however, for evaluating the response and recovery time the range of $35 \%$ to $85 \%$ was used as shown in Figure 9a.

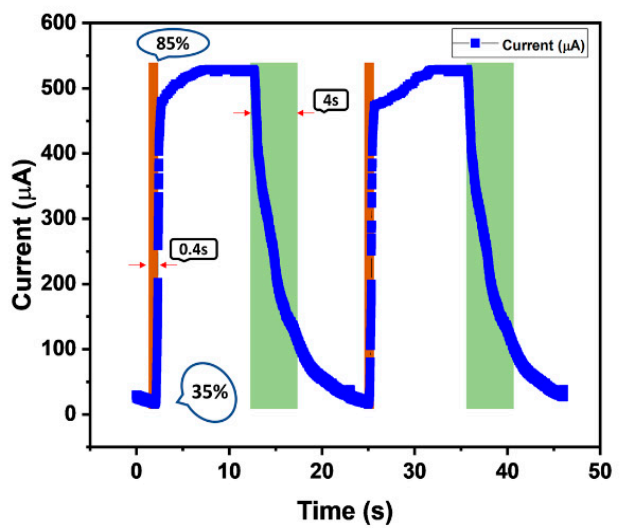

(a)

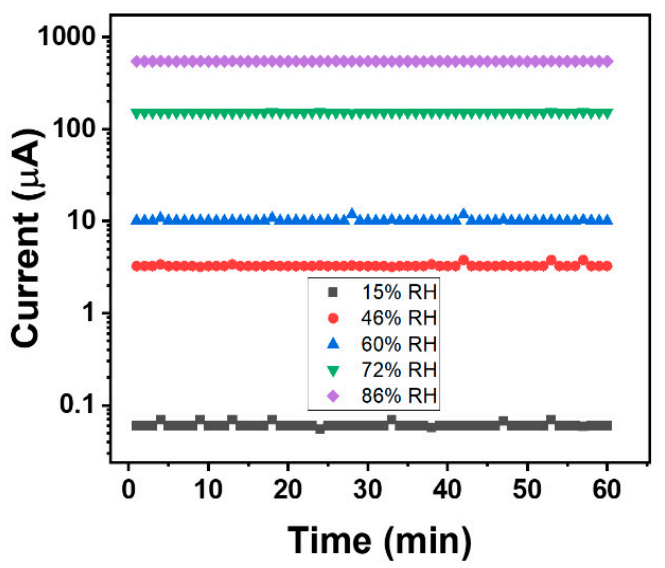

(b)

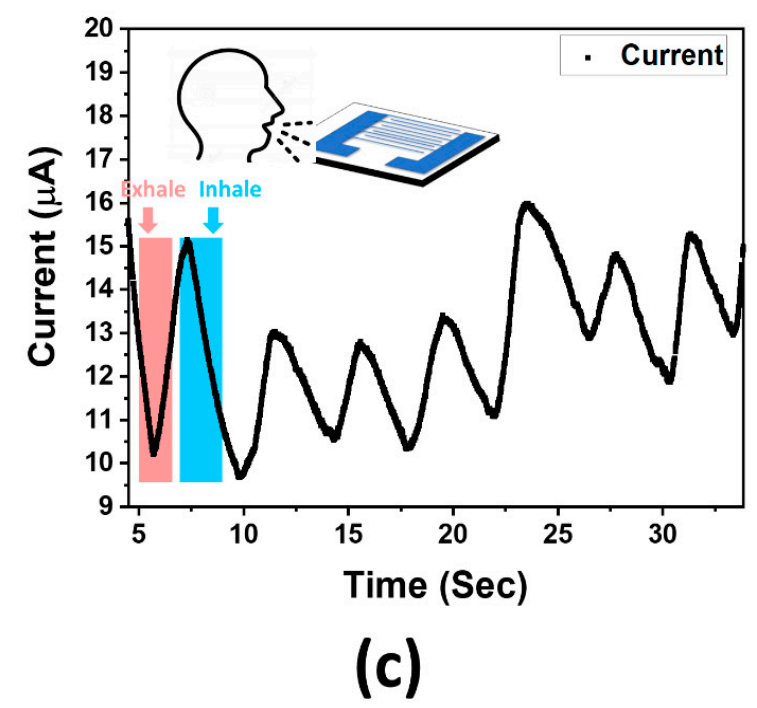

Figure 9. (a) Response and recovery time; (b) stability test of the proposed sensor, (c) sensor response to normal human breathing.

Stability is another key feature to evaluate the performance of a sensor; therefore, we measured the stability of our fabricated humidity sensor by placing it inside jars with different levels of $\mathrm{RH} \%$ at an applied voltage of $3 \mathrm{~V}$ and observed the response of resulting current continuously for $1 \mathrm{~h}$ as shown in Figure $9 \mathrm{~b}$. The fabricated sensor was exposed to five different humidity levels including $15 \%, 46 \%, 60 \%, 72 \%$, and $86 \% \mathrm{RH} \%$ inside their 
respective jars and the current was continuously measured. Figure $9 \mathrm{~b}$ shows that the value of current remained stable at each humidity level.

We tested our fabricated sensor for the application of human health monitoring by exposing its surface to human breathing so that it can sense the water vapors. Our proposed sensor showed a fast response time with a quick recovery time and had the capability of measuring rapid and small $\mathrm{RH} \%$ changes. The sensor response over normal breathing was tested. Figure $9 \mathrm{c}$ depicted the change of current with respect to normal human breathing. As the air was exhaled from the mouth, it contained water vapors; due to these water vapors', conductivity of active layer increased resulting in more current flowing through it. During inhaling, conductivity decreases, hence proving that the $\mathrm{GrF} / \mathrm{ZnO}$ based humidity sensor exhibited an excellent response to breathing. The current change was in the microampere range; therefore, this proposed sensor can possibly be a promising candidate for health monitoring applications.

Graphene and its derivate composites with $\mathrm{ZnO}$ have been reported by many authors for humidity sensing applications. Table 2 compares the performance of such sensors with our proposed device. This comparison table clearly shows that this proposed sensor has fast response and recovery time and is highly sensitive to humidity compared to other $\mathrm{ZnO} /$ Graphene composites.

Table 2. A comparison table of proposed work and the other reported $\mathrm{ZnO} /$ Graphene humidity sensors.

\begin{tabular}{cccccc}
\hline Active Material & $\begin{array}{c}\text { Response } \\
\text { Time (s) }\end{array}$ & $\begin{array}{c}\text { Recovery } \\
\text { Time (s) }\end{array}$ & $\begin{array}{c}\text { Average Sensitivity } \\
\text { (X/\%RH) }\end{array}$ & Range & Reference \\
\hline ZnO/GrF & $\mathbf{0 . 4}$ & $\mathbf{4}$ & $\mathbf{7 . 7} \boldsymbol{\mu A} / \% \mathbf{R H}$ & $\mathbf{1 5 - 8 6 \%}$ & This Work \\
\hline $\begin{array}{c}\text { ZnO nanowires (NWs)/graphene } \\
\text { quantum dots (GQDs) }\end{array}$ & 27 & 12 & $40.16 \mathrm{kHz} / \% \mathrm{RH}$ & $20-90 \%$ & {$[43]$} \\
\hline ZnO/Graphene Foam & 10 & 15 & $33.3 \Omega / \% \mathrm{RH}$ & $20-95 \%$ & {$[42]$} \\
\hline ZnO/PVP-RGO & 12 & 3 & - & $15-95 \%$ & {$[44]$} \\
\hline
\end{tabular}

To improve the humidity sensing properties of $\mathrm{ZnO}$, its composition with other 2D materials like $\mathrm{MoS}_{2}$ [31] and $\mathrm{WS}_{2}$ [32] etc., has also been reported. Table 3 shows the performance comparison of this $\mathrm{GrF} / \mathrm{ZnO}$ composite-based humidity sensor to other 2D materials/ $\mathrm{ZnO}$ composite-based humidity sensors. The performance parameters including response time, recovery time, and sensitivity of the proposed sensor make it a better choice for humidity sensing as compared to other materials.

Table 3. Comparison table of $\mathrm{GrF} / \mathrm{ZnO}$ and other 2D materials/ZnO composite-based humidity sensors.

\begin{tabular}{cccccc}
\hline $\begin{array}{c}\text { Active } \\
\text { Material }\end{array}$ & $\begin{array}{c}\text { Response } \\
\text { Time (s) }\end{array}$ & $\begin{array}{c}\text { Recovery } \\
\text { Time (s) }\end{array}$ & $\begin{array}{c}\text { Average Sensitivity } \\
\text { (X/\%RH) }\end{array}$ & Range & Reference \\
\hline ZnO/GrF & $\mathbf{0 . 4}$ & $\mathbf{4}$ & $\mathbf{7 . 7} \boldsymbol{\mu \mathbf { A } / \% \mathbf { R H }}$ & $\mathbf{1 5 - 8 6 \%}$ & This Work \\
$\mathrm{ZnO} / \mathrm{MoS} 2$ & 1 & 20 & - & $11-95 \%$ & {$[31]$} \\
$\mathrm{ZnO} / \mathrm{WS} 2$ & 74.51 & 25.67 & $101.71 \mathrm{fF} / \% \mathrm{RH}$ & $18-85 \%$ & {$[32]$} \\
\hline
\end{tabular}

Furthermore, graphene composites with different materials like semiconductors [40], 2D materials [35], polymers [40], metal oxides [32], and biopolymers [37], have been reported for humidity sensors. A detailed comparison between this demonstrated $\mathrm{GrF} / \mathrm{ZnO}$ composite and various other graphene composite-based humidity sensors is given in Table 4. The sensing performance sets the reported sensor apart from other humidity sensors. 
Table 4. General comparison of proposed work with different graphene composite-based humidity sensors.

\begin{tabular}{|c|c|c|c|c|c|}
\hline Active Material & Response Time (s) & Recovery Time (s) & $\begin{array}{c}\text { Average Sensitivity } \\
\text { (X/\%RH) }\end{array}$ & Range & Reference \\
\hline $\mathrm{ZnO} / \mathrm{GrF}$ & 0.4 & 4 & $7.7 \mu \mathrm{A} / \% \mathrm{RH}$ & $15-86 \%$ & This Work \\
\hline Graphene film & 0.125 & 0.125 & - & $11-95 \%$ & [51] \\
\hline Graphene oxide film & 0.3 & 0.3 & - & $30-80 \%$ & [52] \\
\hline BP/Graphene & 9 & 30 & $73 \Omega / \% R H$ & $15-70 \%$ & [35] \\
\hline $\mathrm{SiO}$ 2/PVA/Graphene & 24 & 14.4 & $2.429 \mathrm{kHz} / \% \mathrm{RH}$ & $55-90 \%$ & [40] \\
\hline Chitosan/GQD & 36 & 3 & $39.2 \mathrm{~Hz} / \% \mathrm{RH}$ & $11-95 \%$ & [41] \\
\hline $\mathrm{SnO} 2 / \mathrm{RGO}$ & 102 & 6 & $1604.89 \mathrm{pF} / \% \mathrm{RH}$ & $11-97 \%$ & [33] \\
\hline Non-woven fabric/GO & 8.90 & 11.76 & - & $42-90 \%$ & [38] \\
\hline
\end{tabular}

\section{Conclusions}

This work demonstrated an easy, solution-processed, and cost-effective way to fabricate a humidity sensor based on the composite of graphene flower and $\mathrm{ZnO}$. Characterizations by FESEM, EDS, and XRD were carried out to completely understand the properties of $\mathrm{GrF} / \mathrm{ZnO}$ composite. It was observed that $\mathrm{GrF} / \mathrm{ZnO}$ composite had a high surface area with a porous nanowire-like structure, making it a suitable candidate for humidity sensing. Multiple electrical characterizations of the prepared humidity sensors were performed at different $\mathrm{RH} \%$ levels. The proposed humidity sensor showed an increasing current and a decreasing impedance response with respect to increase in $\mathrm{RH} \%$ from $15 \%$ to $86 \%$. The demonstrated sensor showed a fast response with a current change of $7.7 \mu \mathrm{A} / \mathrm{RH} \%$. Moreover, the sensor revealed a fast recovery time and offered good stability over a wide range of humidity. The proposed sensor showed a measurable current change in response to normal human breath, making it a compelling candidate for health monitoring applications. GrF/ZnO composite has excellent morphological, chemical, and electrical properties that make it a useful candidate for many applications.

Supplementary Materials: The following are available online at https:/ /www.mdpi.com/2079-4 991/11/1/242/s1, Figure S1, shows the microscopic and digital camera image of screen-printed interdigitated electrodes. Figure S2, illustrates the setup used for measuring sensors electrical response with respect to $\mathrm{RH} \%$. Figure S3, shows an optimized FESEM and EDS analysis of $\mathrm{ZnO}$ thin film grown by the sol-gel method. Figure S4, shows the capacitance response of the GrF/ZnO-based humidity sensor at different frequencies. Impedance response of $\mathrm{GrF} / \mathrm{ZnO}$-based humidity sensor at different frequencies is depicted in Figure S5.

Author Contributions: Conceptualization, M.S.; investigation, M.S., S.A.K., H.M.M.U.R., Y.Y., S.K., M.M.R. and W.Y.K.; validation, M.S., S.A.K., M.M.R. and W.Y.K.; writing-original draft, M.S.; review and editing, M.S., H.M.M.U.R., Y.Y., S.K., M.M.R. and W.Y.K. All authors have read and agreed to the published version of the manuscript.

Funding: This work was supported by National Research Foundation of Korea (NRF) grant funded by the Korea Government (Ministry of Science and ICT) (NRF-2018R1A4A1025998, 2020H1D3A1A 04081545), and by "Human Resources Program in Energy Technology" of the Korea Institute of Energy Technology Evaluation and Planning (KETEP), granted financial resource from the Ministry of Trade, Industry \& Energy (MOTIE) (No. 20184030202200).

Conflicts of Interest: The authors declare no conflict of interest.

\section{References}

1. Wernecke, R.; Wernecke, J. Industrial Moisture and Humidity Measurement: A Practical Guide—Roland Wernecke, Jan Wernecke—Google Books; WILEY-VCH: Weinheim, Germany, 2014.

2. Humidity Sensor Market Size, Share \& Forecast Report 2019-2025. In KBV Research; 2019. Available online: https://www. kbvresearch.com/humidity-sensor-market/ (accessed on 10 November 2020).

3. Humidity Sensor Market Size, Share I Global Industry Report, 2019-2025. In Grand View Research; 2019. Available online: https://www.grandviewresearch.com/industry-analysis/humidity-sensor-market/toc (accessed on 10 November 2020). 
4. Smith, A.D.; Elgammal, K.; Niklaus, F.; Delin, A.; Fischer, A.C.; Vaziri, S.; Forsberg, F.; Råsander, M.; Hugosson, H.; Bergqvist, L.; et al. Resistive graphene humidity sensors with rapid and direct electrical readout. Nanoscale 2015, 7, 19099-19109. [CrossRef]

5. Rahim, I.; Shah, M.; Khan, A.; Luo, J.; Zhong, A.; Li, M.; Ahmed, R.; Li, H.; Wei, Q.; Fu, Y. Capacitive and resistive response of humidity sensors based on graphene decorated by PMMA and silver nanoparticles. Sens. Actuators B Chem. 2018, $267,42-50$. [CrossRef]

6. Lv, C.; Hu, C.; Luo, J.; Liu, S.; Qiao, Y.; Zhang, Z.; Song, J.; Shi, Y.; Cai, J.; Watanabe, A. Recent advances in graphene-based humidity sensors. Nanomaterials 2019, 9, 422. [CrossRef]

7. Najeeb, M.A.; Ahmad, Z.; Shakoor, R.A. Organic Thin-Film Capacitive and Resistive Humidity Sensors: A Focus Review. Adv. Mater. Interfaces 2018, 5, 1-19. [CrossRef]

8. Cho, M.; Kim, S.; Kim, I.; Kim, E.; Wang, Z.; Kim, N.; Kim, S.; Oh, J. Perovskite-Induced Ultrasensitive and Highly Stable Humidity Sensor Systems Prepared by Aerosol Deposition at Room Temperature. Adv. Funct. Mater. 2020, 30, 1907449. [CrossRef]

9. Jlassi, K.; Mallick, S.; Mutahir, H.; Ahmad, Z.; Touati, F. Synthesis of In Situ Photoinduced Halloysite-Polypyrrole@Silver Nanocomposite for the Potential Application in Humidity Sensors. Nanomaterials 2020, 10, 1426. [CrossRef]

10. Hwang, B.-Y.; Du, W.; Lee, H.-J.; Kang, S.; Takada, M.; Kim, J.-Y. Stretchable and High-performance Sensor films Based on Nanocomposite of Polypyrrole/SWCNT/Silver Nanowire. Nanomaterials 2020, 10, 696. [CrossRef] [PubMed]

11. Khan, M.U.; Hassan, G.; Bae, J. Bio-compatible organic humidity sensor based on natural inner egg shell membrane with multilayer crosslinked fiber structure. Sci. Rep. 2019, 9. [CrossRef]

12. Dai, J.; Zhao, H.; Lin, X.; Liu, S.; Liu, Y.; Liu, X.; Fei, T.; Zhang, T. Ultrafast Response Polyelectrolyte Humidity Sensor for Respiration Monitoring. ACS Appl. Mater. Interfaces 2019. [CrossRef]

13. Soomro, A.M.; Jabbar, F.; Ali, M.; Lee, J.W.; Mun, S.W.; Choi, K.H. All-range flexible and biocompatible humidity sensor based on poly lactic glycolic acid (PLGA) and its application in human breathing for wearable health monitoring. J. Mater. Sci. Mater. Electron. 2019, 30, 9455-9465. [CrossRef]

14. Rehman, M.M.; Siddiqui, G.U.; ur Rehman, M.M.; Kim, H.B.; Doh, Y.H.; Choi, K.H. 2D nanocomposite of hexagonal boron nitride nanoflakes and molybdenum disulfide quantum dots applied as the functional layer of all-printed flexible memory device. Mater. Res. Bull. 2018, 105, 28-35. [CrossRef]

15. Horzum, N.; Taşçioglu, D.; Okur, S.; Demir, M.M. Humidity sensing properties of ZnO-based fibers by electrospinning. Talanta 2011, 85, 1105-1111. [CrossRef] [PubMed]

16. Khan, M.U.; Hassan, G.; Awais, M.; Bae, J. All printed full range humidity sensor based on Fe2O3. Sens. Actuators A Phys. 2020, 311, 112072. [CrossRef]

17. Velumani, M.; Meher, S.R.; Alex, Z.C. Composite metal oxide thin film based impedometric humidity sensors. Sens. Actuators B Chem. 2019, 301, 127084. [CrossRef]

18. Farzaneh, A.; Mohammadzadeh, A.; Esrafili, M.D.; Mermer, O. Experimental and theoretical study of TiO 2 based nanostructured semiconducting humidity sensor. Ceram. Int. 2019, 45, 8362-8369. [CrossRef]

19. Irawati, N.; Rahman, H.A.; Ahmad, H.; Harun, S.W. A PMMA microfiber loop resonator based humidity sensor with ZnO nanorods coating. Meas. J. Int. Meas. Confed. 2017, 99, 128-133. [CrossRef]

20. Gu, L.; Zheng, K.; Zhou, Y.; Li, J.; Mo, X.; Patzke, G.R.; Chen, G. Humidity sensors based on ZnO/TiO2 core/shell nanorod arrays with enhanced sensitivity. Sens. Actuators B Chem. 2011, 159, 1-7. [CrossRef]

21. Dai, H.; Feng, N.; Li, J.; Zhang, J.; Li, W. Chemiresistive humidity sensor based on chitosan/zinc oxide/single-walled carbon nanotube composite film. Sens. Actuators B Chem. 2019, 283, 786-792. [CrossRef]

22. Wang, W.; Li, Z.; Liu, L.; Zhang, H.; Zheng, W.; Wang, Y.; Huang, H.; Wang, Z.; Wang, C. Humidity sensor based on LiCl-doped ZnO electrospun nanofibers. Sens. Actuators B Chem. 2009, 141, 404-409. [CrossRef]

23. Yu, S.; Zhang, H.; Chen, C.; Lin, C. Investigation of humidity sensor based on Au modified ZnO nanosheets via hydrothermal method and first principle. Sens. Actuators B Chem. 2019, 287, 526-534. [CrossRef]

24. Ismail, A.S.; Mamat, M.H.; Yusoff, M.M.; Malek, M.F.; Zoolfakar, A.S.; Rani, R.A.; Suriani, A.B.; Mohamed, A.; Ahmad, M.K.; Rusop, M. Enhanced humidity sensing performance using Sn-Doped $\mathrm{ZnO}$ nanorod Array $/ \mathrm{SnO}_{2}$ nanowire heteronetwork fabricated via two-step solution immersion. Mater. Lett. 2018, 210, 258-262. [CrossRef]

25. Chang, S.P.; Chang, S.J.; Lu, C.Y.; Li, M.J.; Hsu, C.L.; Chiou, Y.Z.; Hsueh, T.J.; Chen, I.C. A ZnO nanowire-based humidity sensor. Superlattices Microstruct. 2010, 47, 772-778. [CrossRef]

26. Bu, I.Y.Y.; Yang, C.C. High-performance ZnO nanoflake moisture sensor. Superlattices Microstruct. 2012, 51, 745-753. [CrossRef]

27. Yusof, H.H.M.; Harun, S.W.; Dimyati, K.; Bora, T.; Sterckx, K.; Mohammed, W.S.; Dutta, J. Low-Cost Integrated Zinc Oxide Nanorod-Based Humidity Sensors for Arduino Platform. IEEE Sens. J. 2019, 19, 2442-2449. [CrossRef]

28. Erol, A.; Okur, S.; Comba, B.; Mermer, Ö.; Arikan, M.Ç. Humidity sensing properties of ZnO nanoparticles synthesized by sol-gel process. Sens. Actuators B Chem. 2010, 145, 174-180. [CrossRef]

29. Hsu, N.F.; Chang, M.; Lin, C.H. Synthesis of ZnO thin films and their application as humidity sensors. In Microsystem Technologies; Springer: Berlin/Heidelberg, Germany, 2013; Volume 19, pp. 1737-1743. [CrossRef]

30. Hassan, G.; Bae, J.; Lee, C.H.; Hassan, A. Wide range and stable ink-jet printed humidity sensor based on graphene and zinc oxide nanocomposite. J. Mater. Sci. Mater. Electron. 2018, 29, 5806-5813. [CrossRef]

31. Ze, L.; Yueqiu, G.; Xujun, L.; Yong, Z. MoS2-modified ZnO quantum dots nanocomposite: Synthesis and ultrafast humidity response. Appl. Surf. Sci. 2017, 399, 330-336. [CrossRef] 
32. Dwiputra, M.A.; Fadhila, F.; Imawan, C.; Fauzia, V. The enhanced performance of capacitive-type humidity sensors based on ZnO nanorods/WS2 nanosheets heterostructure. Sens. Actuators B Chem. 2020, 310, 127810. [CrossRef]

33. Zhang, D.; Chang, H.; Li, P.; Liu, R.; Xue, Q. Fabrication and characterization of an ultrasensitive humidity sensor based on metal oxide/graphene hybrid nanocomposite. Sens. Actuators B Chem. 2016, 225, 233-240. [CrossRef]

34. Ali, S.; Hassan, A.; Hassan, G.; Bae, J.; Lee, C.H. All-printed humidity sensor based on gmethyl-red/methyl-red composite with high sensitivity. Carbon N. Y. 2016, 105, 23-32. [CrossRef]

35. Phan, D.T.; Park, I.; Park, A.R.; Park, C.M.; Jeon, K.J. Black P/graphene hybrid: A fast response humidity sensor with good reversibility and stability. Sci. Rep. 2017, 7, 1-7. [CrossRef] [PubMed]

36. Chen, C.; Wang, X.; Li, M.; Fan, Y.; Sun, R. Humidity sensor based on reduced graphene oxide/lignosulfonate composite thin-film. Sens. Actuators B Chem. 2018, 255, 1569-1576. [CrossRef]

37. He, P.; Brent, J.R.; Ding, H.; Yang, J.; Lewis, D.J.; O’Brien, P.; Derby, B. Fully printed high performance humidity sensors based on two-dimensional materials. Nanoscale 2018, 10, 5599-5606. [CrossRef] [PubMed]

38. Wang, Y.; Zhang, L.; Zhang, Z.; Sun, P.; Chen, H. High-Sensitivity Wearable and Flexible Humidity Sensor Based on Graphene Oxide/Non-Woven Fabric for Respiration Monitoring. Langmuir 2020, 36, 9443-9448. [CrossRef] [PubMed]

39. Chani, M.T.S.; Karimov, K.S.; Meng, H.; Akhmedov, K.M.; Murtaza, I.; Asghar, U.; Abbass, S.Z.; Ali, R.; Asiri, A.M.; Nawaz, N. Humidity Sensor Based on Orange Dye and Graphene Solid Electrolyte Cells. Russ. J. Electrochem. 2019, 55, 1391-1396. [CrossRef]

40. Su, Y.; Li, C.; Li, M.; Li, H.; Xu, S.; Qian, L.; Yang, B. Surface acoustic wave humidity sensor based on three-dimensional architecture graphene/PVA $/ \mathrm{SiO}_{2}$ and its application for respiration monitoring. Sens. Actuators B Chem. 2020, $308,127693$. [CrossRef]

41. Qi, P.; Zhang, T.; Shao, J.; Yang, B.; Fei, T.; Wang, R. A QCM humidity sensor constructed by graphene quantum dots and chitosan composites. Sens. Actuators A Phys. 2019, 287, 93-101. [CrossRef]

42. Morsy, M.; Ibrahim, M.; Yuan, Z.; Meng, F. Graphene Foam Decorated with ZnO as a Humidity Sensor. IEEE Sens. J. 2020, 20, 1721-1729. [CrossRef]

43. Wu, J.; Yin, C.; Zhou, J.; Li, H.; Liu, Y.; Shen, Y.; Garner, S.; Fu, Y.; Duan, H. Ultrathin Glass-Based Flexible, Transparent, and Ultrasensitive Surface Acoustic Wave Humidity Sensor with ZnO Nanowires and Graphene Quantum Dots. ACS Appl. Mater. Interfaces 2020, 12, 39817-39825. [CrossRef]

44. Yang, H.; Ye, Q.; Zeng, R.; Zhang, J.; Yue, L.; Xu, M.; Qiu, Z.-J.; Wu, D. Stable and Fast-Response Capacitive Humidity Sensors Based on a ZnO Nanopowder/PVP-RGO Multilayer. Sensors 2017, 17, 2415. [CrossRef]

45. Zhang, D.; Liu, J.; Xia, B. Layer-by-Layer Self-Assembly of Zinc Oxide/Graphene Oxide Hybrid Toward Ultrasensitive Humidity Sensing. IEEE Electron Device Lett. 2016, 37, 916-919. [CrossRef]

46. Zafar, M.; Yun, J.Y.; Kim, D.H. Improved inverted-organic-solar-cell performance via sulfur doping of ZnO films as electron buffer layer. Mater. Sci. Semicond. Process. 2019, 96, 66-72. [CrossRef]

47. Toe, M.Z.; Jusoh, N.A.H.N.; Pung, S.Y.; Yaacob, K.A.; Matsuda, A.; Tan, W.K.; Han, S.S. Effect of ZnO seed layer on the growth of ZnO nanorods on silicon substrate. In Materials Today: Proceedings; Elsevier: Amsterdam, The Netherlands, 2019; Volume 17, pp. 553-559. [CrossRef]

48. Chen, S.N.; Huang, M.Z.; Lin, Z.H.; Liu, C.P. Enhancing charge transfer for ZnO nanorods based triboelectric nanogenerators through Ga doping. Nano Energy 2019, 65, 104069. [CrossRef]

49. Li, X.; Wang, Z.; Qiu, Y.; Pan, Q.; Hu, P. 3D graphene/ZnO nanorods composite networks as supercapacitor electrodes. J. Alloys Compd. 2015, 620, 31-37. [CrossRef]

50. Cai, R.; Wu, J.G.; Sun, L.; Liu, Y.J.; Fang, T.; Zhu, S.; Li, S.Y.; Wang, Y.; Guo, L.F.; Zhao, C.E.; et al. 3D graphene/ZnO composite with enhanced photocatalytic activity. Mater. Des. 2016, 90, 839-844. [CrossRef]

51. Zhen, Z.; Li, Z.; Zhao, X.; Zhong, Y.; Zhang, L.; Chen, Q.; Yang, T.; Zhu, H. Formation of Uniform Water Microdroplets on Wrinkled Graphene for Ultrafast Humidity Sensing. Small 2018, 14, 1703848. [CrossRef]

52. Borini, S.; White, R.; Wei, D.; Astley, M.; Haque, S.; Spigone, E.; Harris, N.; Kivioja, J.; Ryhänen, T. Ultrafast graphene oxide humidity sensors. ACS Nano 2013, 7, 11166-11173. [CrossRef] 